\title{
$\operatorname{vanA}$ 유전자를 지닌 Vancomycin 내성 장구균의 VanB 표현형 발현 기전
}

\author{
박일중 $\cdot$ 이위교 ${ }^{2} \cdot$ 이혁민 ${ }^{3} \cdot$ 용동은 $\cdot$ 이경원 ${ }^{4} \cdot$ 김의종 $\cdot$ 정석훈 ${ }^{6} \cdot$ 박연준 $^{7} \cdot$ 최태열 ${ }^{8}$ 어 영 $\cdot$ 신종희 ${ }^{1} \cdot$ 이종욱 ${ }^{11}$ 안지영 ${ }^{12}$ \\ 이성희 $\left.\right|^{13} \cdot$ 우건조 $^{14}$
}

아주의대 가정의학교실', 아주의대 진단검사의학교실, 관동의대 진단검사의학교실, 연세의대 진단검사의학교실, 서울의대 진단검사의학교실, 고신의대 진단검사의학교실, 가톨릭의대 진단검사의학교실 ${ }^{2}$ 한양의대 진단검사의학교실, 원주의대 진단검사의학교실, 전남의대 진단검사의학교실" 건양의대 진단검사의학교실", 순천향의대 진단검사의학교실', 제주한마음병원 진단검사의학과 ${ }^{3}$, 식품의약품안전청 식품안전평가부 식품미생물과 ${ }^{4}$

\section{Mechanism of VanB Phenotype in Vancomycin-Resistant Enterococci carrying vanA gene}

Il Joong Park, M.D. ${ }^{1}$, Wee Gyo Lee, M.D. ${ }^{2}$, Hyukmin Lee, M.D. ${ }^{3}$, Dongeun Yong, M.D. ${ }^{4}$, Kyungwon Lee, M.D. ${ }^{4}$, Eui-Chong Kim, M.D. ${ }^{5}$, Seok Hoon Jeong, M.D. ${ }^{6}$, Yeon Jun Park, M.D. ${ }^{7}$, Tae Yeal Choi, M.D. ${ }^{8}$, Young Uh, M.D. ${ }^{9}$, Jong Hee Shin, M.D. ${ }^{10}$, Jongwook Lee, M.D. ${ }^{11}$, Ji young Ahn, M.D. ${ }^{12}$, Sung-Hee Lee, M.D. ${ }^{13}$, and Gun-Jo Woo, Ph.D. ${ }^{14}$

Departments of Family Medicine ${ }^{1}$ and Laboratory Medicine ${ }^{2}$, Ajou University School of Medicine, Suwon; Departments of Laboratory Medicine, University of Kwandong College of Medicine ${ }^{3}$, Goyang; Yonsei University College of Medicine ${ }^{4}$, Seoul; Seoul University College of Medicine $^{5}$, Seoul; Kosin University College of Medicine ${ }^{6}$, Busan; The Catholic University of Korea College of Medicine ${ }^{7}$, Seoul; Hanyang University College of Medicine ${ }^{8}$, Seoul; Yonsei University Wonju University College of Medicine ${ }^{9}$, Wonju; Chonnam National University College of Medicine ${ }^{10}$, Gwangju; Keonyang University College of Medicine ${ }^{11}$, Daejeon; Sooncheonhyang University College of Medicine ${ }^{12}$, Gumi; Cheju Hanmaeum Hospital' ${ }^{13}$, Jeju; Center for Food Safety Evaluation ${ }^{14}$, Korea Food and Drug Administration, Seoul, Korea

\begin{abstract}
Background : Recently, vancomycin-resistant enterococci (VRE) with the vanA genotype that are susceptible to teicoplanin have been described in Japan, Taiwan, and Korea. The investigators suggested three point mutations in the putative sensor domain of vanS or impairment of accessory proteins VanY and VanZ as an explanation for the VanB phenotype-vanA genotype VRE. In this study, we analyzed Tn 1546-like elements to determine the molecular mechanisms responsible for the impaired glycopeptide resistance of clinical VRE isolates with VanB phenotype-vanA genotype from Korea.

Methods : From 2001 to 2004, 28 clinical isolates of Enterococcus faecium with VanB phenotypevanA genotype were collected from 8 different university hospitals in diverse geographic areas in Korea. For structural analysis of Tn1546-like elements, PCR amplifications for internal regions of Tn 1546 were performed. The purified PCR products were directly sequenced with an ABI Prism 3100 DNA sequencer.

Results : The sequence data of the vanS regulatory gene revealed that none of the isolates had any point mutations in this gene. All 28 isolates had a complete or incomplete deletion of vanY gene. Of these, 13 strains represented a complete deletion of vanZ, and 2 strains showed the deletion of nucleotides near the end point of $\operatorname{van} X$.

Conclusions : The mechanism of VanB phenotype-vanA genotype in VRE isolates from Korea is not point mutations of vanS but the rearrangements of vanX, vanY and vanZ. (Korean J Lab Med 2006;26: 412-7)
\end{abstract}

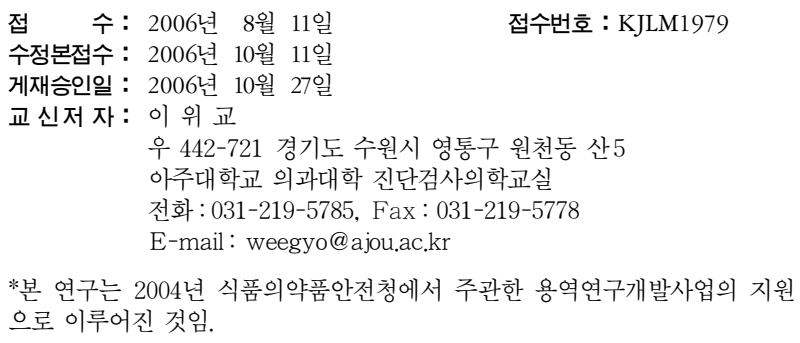

Key Words : VRE, VanB, vanA, vanS, vanX, $\operatorname{vanY}, \operatorname{van} Z$

\section{서 론}

Vancomycin 내성 장구균(vancomycin-resistant enterococci, $\mathrm{VRE})$ 은 1986년 영국과 프랑스에서 처음으로 보고되었고, 일년 
후 미국에서도 보고 된 이래 발생이 급격히 증가하고 있다[1, 2]. 미국 국가 병원감염 감독위원회(National Nosocomial Infections Surveillance System, NNIS)에서는 중환자실에서 분리되는 장구 균 중 $\mathrm{VRE}$ 의 비율이 1989 년에 $0.4 \%$ 에서 1993 년에는 $13.6 \%$ 로 증가하였으며, 2004년까지 31.3\%로 급증하였음을 보고 하였다[3, 4]. 국내에서는 1992년 박 등이 백혈병 환자의 가검물에서 vancomycin에 고도내성을 보이는 Enterococcus durans 1주를 보고 하였고, 이후 1997년까지 VRE의 분리빈도는 매우 낮았으나 1998 년부터 경구용 vancomycin 사용의 증가와 더불어 현저하게 증가 하고 있다[5, 6].

장구균의 vancomycin 내성 표현형 $\operatorname{VanA}, \operatorname{VanB}, \operatorname{VanC}$, $\operatorname{VanD}, \operatorname{VanE}$ 및 $\operatorname{VanG}$ 중에서 $\operatorname{VanA}$ 와 $\operatorname{VanB}$ 가 임상적으로 의미 있으며, 일반적으로 유전형과 표현형이 일치한다[7-12]. 즉, vancomycin과 teicoplanin에 내성을 보이는 $\operatorname{VanA}$ 형의 경우 $\operatorname{van} A$ 유전자를, vancomycin에는 내성이나 teicoplanin에 감수성인 $\operatorname{VanB}$ 형의 경우 $\operatorname{van} B$ 유전자를 보유한다. 최근 $\operatorname{VanB}$ 표현형을 보이 나 $\operatorname{van} A$ 유전자를 갖는 VanB phenotype-vanA genotype VRE 가 보고된 바 있다. Hashimoto 등[13]은 $\operatorname{van} A$ 유전형 VRE에 서 teicoplanin에 감수성을 보이는 것은 $\operatorname{vanS}$ domain의 3 개의 점돌연변이가 원인인 것으로 설명하였으며, 태국 및 한국에서도 이와 같이 보고한 바 있다[14, 15]. 그러나, 이와는 다른 원인으 로 $\operatorname{van} Y$ 와 $\operatorname{vanZ}$ 의 단백질들의 결실 혹은 변형을 생각할 수 있으 며, 최근 한국에서 $\operatorname{VanB}$ phenotype-vanA genotype VRE 5예 중 한 균주에서 $\operatorname{van} X$ 의 부분 결실을, 다른 4 균주에서 $\operatorname{van} Y$ 또는 $\operatorname{vanZ}$ 유전자의 결실이 있음을 보고한 바 있다[16]. 본 연구에서 는 한국에서 발생하는 VanB phenotype-vanA genotype VRE 의 발현 기전을 알아보고자 국내 대학병원에서 분리된 $\operatorname{VanB}$ phenotype-vanA genotype VRE 균주의 유전자 분석 및 염기서열 분석을 통하여 분자생물학적 발현 기전을 확인하고자 하였다.

\section{대상 및 방법}

\section{1. 연구대상 및 세균 동정}

2001년 1월부터 2004년 12월까지 전국 8개 대학병원에서 수집 한 디스크 확산법상 표현형이 $\mathrm{VanB}$ 형인 VRE 28균주를 대상으 로 하였다. 각 균주는 vancomycin $6 \mathrm{mg} / \mathrm{L}$ 을 함유한 brain heart infusion agar를 이용하여 선택 한천 배지법으로 vancomycin 내 성여부를 검색하였고, $\mathrm{VRE}$ 로 검색된 모든 균주에 대하여 기존의 수기법, API 20 STREP (bioMerieux, Hazelwood, MO, USA) 및 Vitek system (bioMerieux)을 이용하여 동정하였다. 각 균주 의 vancomycin, teicoplanin 최소억제농도(minimum inhibitory concentration, MIC) 측정을 위하여 E-test를 시행하였다[17].

\section{2. 역학적 연관성 분석}

Pulsed-field gel electrophoresis (PFGE)는 다음과 같이 시행 하였다. Murray 등[18]이 기술한 바와 같이 $\mathrm{SmaI}$ 으로 $25^{\circ} \mathrm{C}$ 에서 처리한 후 ramped pulse time을 시작 1초 및 끝 20초로 하였으 며, $6 \mathrm{~V} / \mathrm{cm}, 24$ 시간 전기영동 하였다. 이후 banding pattern은 Bio-Gene software (Vilber Lourmat, Marne la-valles, France) 를 이용하여 비가중평균결합법(unweighted pair group method with arithmetic average, UPGMA) 법으로 군집 분석하여 역학 적 연관성을 결정하였다.

\section{3. 유전자 구조 분석}

$\operatorname{van} A$ gene cluster가 포함된 transposon $\operatorname{Tn} 1546$ 내부를 중 복되도록 증폭한 후 표준 균주인 E. faecium BM4147[8]과 비 교하는 PCR 지도화(mapping)를 시행하였고, 증폭산물 중 원형 (prototype)과 비교하여 크게 증폭된 부분에 대하여 IS $1216 \mathrm{~V}$ 및 IS1542에 대한 PCR을 시행하여 내성유전자의 구조를 분석하였다.

\section{4. 유전자 염기 서열 분석 및 핵산부합법(Nucleic acid hybridization)}

유전자 변형이 발생한 부위 및 vanS domain에 대한 유전자 염 기 서열 분석 및 핵산부합법을 시행하였다. $\mathrm{PCR}$ 증폭 산물을 전 기 영동한 후에 한천으로부터 GENECLEAN kit (Qbiogene Inc, Carlsbad, CA, USA)를 이용하여 추출한 후, $\mathrm{ABI}$ Prism 3100 DNA SEQUENCER (Applied Biosystems, Foster City, CA, USA)를 사용하여 염기 서열을 분석한 후, DNASIS v2.6 (Hitachi Software, San Francisco, CA, USA)를 이용하여 내성 유전 자의 구조를 판독하였다. 유전자 결실 부위 확인을 위하여 Tn1546 내부 증폭산물을 이용하여 핵산부합법을 시행하였다.

\section{결 과}

\section{1. 세균 동정 및 최저발육저지농도}

대상 균주 28균주 모두 E. faecium으로 동정되었다. E-test에 의한 MIC 검사 결과 vancomycin에 대하여는 대상 균주 모두 고도내성이었고, teicoplanin에 대하여는 감수성 혹은 중간이었다 (Table 1).

\section{2. 유전적 형별 분석}

$\mathrm{PFGE}$ 를 이용한 28균주의 유전적 형별분석 결과 역학적으로 연관성이 없었다(Fig. 1). 
Table 1. MICs of vancomycin and teicoplanin for clinical VRE isolates with VanB phenotype-vanA

\begin{tabular}{|c|c|c|c|c|c|}
\hline \multirow[b]{2}{*}{ Isolates } & \multirow[b]{2}{*}{ Species } & \multicolumn{2}{|c|}{ Vancomycin } & \multicolumn{2}{|c|}{ Teicoplanin } \\
\hline & & $\begin{array}{c}\text { MIC } \\
(\mathrm{mg} / \mathrm{L})\end{array}$ & $\begin{array}{c}\text { Suscep- } \\
\text { tibility }\end{array}$ & $\begin{array}{l}\mathrm{MIC} \\
(\mathrm{mg} / \mathrm{L})\end{array}$ & $\begin{array}{l}\text { Suscep- } \\
\text { tibility }\end{array}$ \\
\hline J1 & E. faecium & $>256$ & $\mathrm{R}$ & 16 & I \\
\hline J2 & E. faecium & $>256$ & $\mathrm{R}$ & 16 & I \\
\hline J3 & E. faecium & $>256$ & $\mathrm{R}$ & 12 & I \\
\hline J4 & E. faecium & $>256$ & $\mathrm{R}$ & 12 & I \\
\hline J5 & E. faecium & $>256$ & $\mathrm{R}$ & 12 & I \\
\hline J6 & E. faecium & $>256$ & $\mathrm{R}$ & 12 & I \\
\hline J7 & E. faecium & $>256$ & $\mathrm{R}$ & 16 & I \\
\hline J8 & E. faecium & $>256$ & $\mathrm{R}$ & 16 & I \\
\hline J9 & E. faecium & $>256$ & $\mathrm{R}$ & 4 & S \\
\hline J10 & E. faecium & $>256$ & $\mathrm{R}$ & 12 & I \\
\hline J11 & E. faecium & $>256$ & $\mathrm{R}$ & 8 & S \\
\hline J12 & E. faecium & $>256$ & $\mathrm{R}$ & 24 & I \\
\hline J13 & E. faecium & $>256$ & $\mathrm{R}$ & 16 & I \\
\hline J14 & E. faecium & $>256$ & $\mathrm{R}$ & 16 & I \\
\hline J15 & E. faecium & $>256$ & $\mathrm{R}$ & 1 & S \\
\hline J16 & E. faecium & $>256$ & $\mathrm{R}$ & 24 & I \\
\hline J17 & E. faecium & $>256$ & $\mathrm{R}$ & 16 & I \\
\hline J18 & E. faecium & $>256$ & $\mathrm{R}$ & 24 & I \\
\hline J19 & E. faecium & $>256$ & $\mathrm{R}$ & 16 & I \\
\hline J2O & E. faecium & $>256$ & $\mathrm{R}$ & 24 & I \\
\hline J21 & E. faecium & $>256$ & $\mathrm{R}$ & 2 & S \\
\hline J22 & E. faecium & $>256$ & $\mathrm{R}$ & 12 & I \\
\hline J23 & E. faecium & $>256$ & $\mathrm{R}$ & 1 & S \\
\hline J24 & E. faecium & $>256$ & $\mathrm{R}$ & 8 & $S$ \\
\hline J25 & E. faecium & $>256$ & $\mathrm{R}$ & 12 & I \\
\hline J26 & E. faecium & $>256$ & $\mathrm{R}$ & 8 & S \\
\hline J27 & E. faecium & $>256$ & $\mathrm{R}$ & 6 & S \\
\hline J28 & E. faecium & $>256$ & $\mathrm{R}$ & 16 & I \\
\hline
\end{tabular}

Abbrebiations: R, resistant; I, intermediate; S, susceptible.

\section{3. 유전자 구조 및 염기서열 분석}

28 균주의 $\operatorname{vanS}$ 유전자에 대한 염기서열 분석 결과 변이여부를 관찰할 수 없었다(Fig. 2). vanA gene cluster의 유전자 변형부 위의 염기서열을 분석하여 28균주 모두 IS1216V가 $\operatorname{van} X-\operatorname{van} Y$ intergenic region (nt8625-9051)에 삽입되면서 $\operatorname{van} Y$ 및 $\operatorname{van} Z$ 유전자 완전 결실 혹은 부분 결실을 확인하였다. 이 중 13 균주 $(\mathrm{J} 2$, $\mathrm{J} 9, \mathrm{~J} 14, \mathrm{~J} 15, \mathrm{~J} 20, \mathrm{~J} 22, \mathrm{~J} 24, \mathrm{~J} 25, \mathrm{~J} 27, \mathrm{~J} 28, \mathrm{~J} 10, \mathrm{~J} 12$ 및 J16)는 IS1216v가 vanA gene cluster 중 nt8712, nt8832 및 nt8845 위 치에 삽입되면서 nt 9355 까지 총 523-643 bp의 염기 손실이 발생 하여 $\operatorname{van} Y$ 의 부분 결실(220-340 bp)이 있었고, BY*로 구분하 였다. 다른 13 균주 $(\mathrm{J} 1, \mathrm{~J} 4, \mathrm{~J} 5, \mathrm{~J} 13, \mathrm{~J} 6, \mathrm{~J} 7, \mathrm{~J} 8, \mathrm{~J} 11, \mathrm{~J} 18, \mathrm{~J} 19, \mathrm{~J} 23$, $\mathrm{J} 21$ 및 J17)에서는 IS $1216 \mathrm{v}$ 의 삽입에 의한 $\operatorname{van} Y$ 및 $\operatorname{van} Z$ 의 완 전 결실을 관찰할 수 있었고, $\mathrm{B} *$ 로 구분하였다. 나머지 2 균주 $(\mathrm{J} 3$, $\mathrm{J} 26)$ 는 vanX의 마지막 위치(nt8624) 인근인 nt8649와 nt8694에 서 IS1216v의 삽입에 의한 손실이 있었으며, BX*로 구분하였다.

Orf2-vanR intergenic region에 삽입된 삽입서열(insertional sequences, IS)의 종류에 따라 추가 분류하였다. 즉, IS $1216 \mathrm{v}$ 가

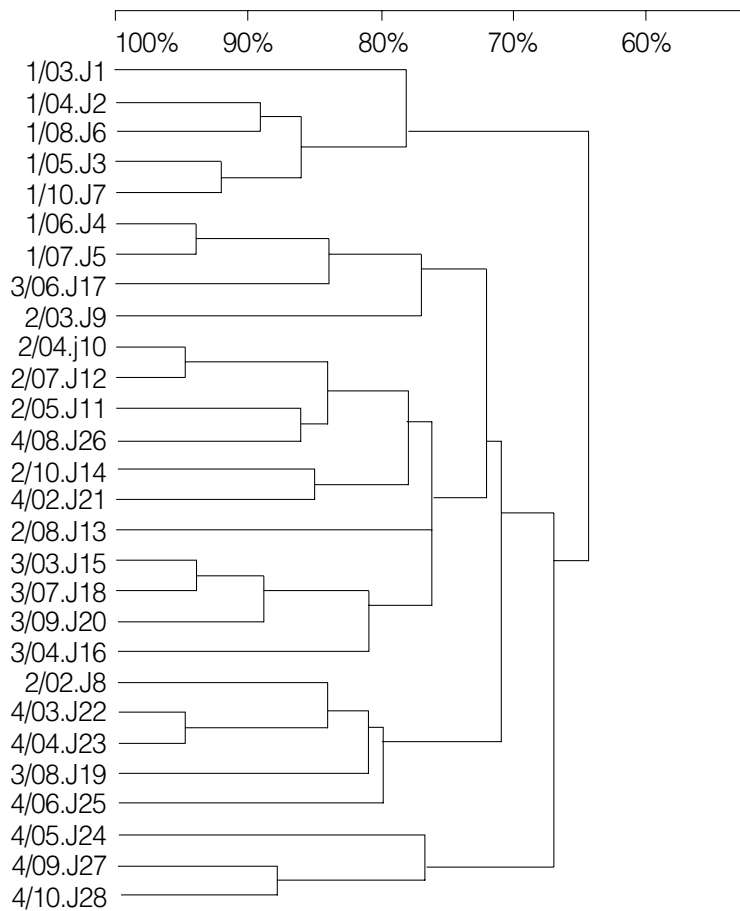

Fig. 1. Dendrogram of $E$. faecium isolates with VanB phenotypevanA. To produce the dendrogram, the banding patterns of $E$. faecium isolates were interpreted by Dice analysis and analysis by the unweighted pair group method with arithmetic averages.

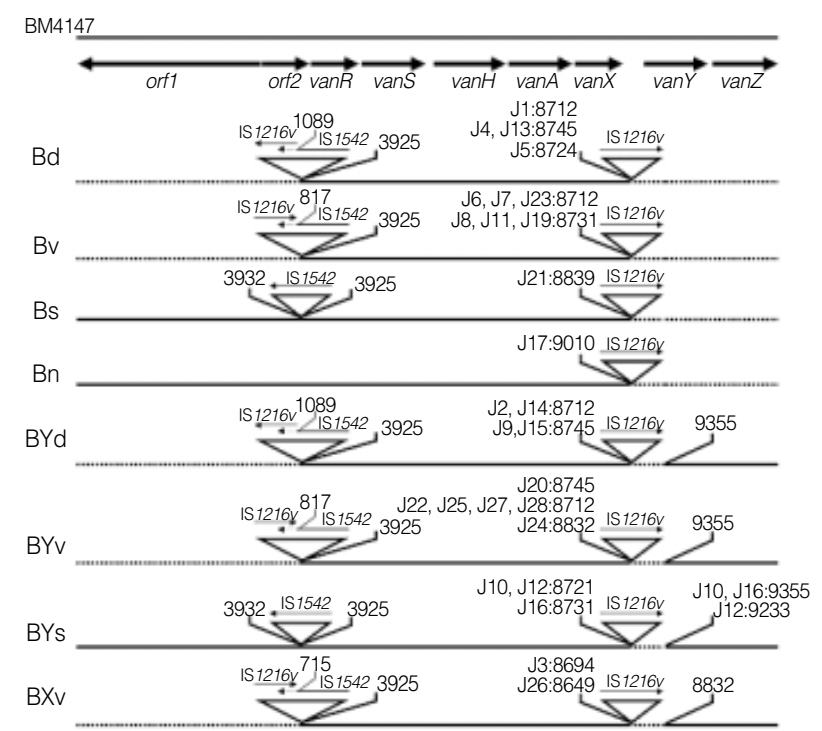

Fig. 2. The genetic maps of $\operatorname{Tn} 1546$ types of $E$. faecium isolates with VanB phenotype-vanA genotype from Korean hospitals. The positions of genes and open reading frames (orf1 and orf2) and the direction of transcription are marked by dark arrows at the top. The inverted triangles represent IS elements. The positions of the first nucleotide upstream and the first nucleotide downstream from the IS insertion sites are depicted. Solid arrows indicate the transcriptional orientation of the inserted IS elements. Deletions are indicated by dotted lines. 
$\mathrm{IS} 1542$ 에 순방향으로 삽입된 군은 *d (Bd 및 BYd)로, IS1216V 가 $\mathrm{IS} 1542$ 에 역방향으로 삽입된 군은 *v $(\mathrm{Bv}, \mathrm{BYv}$ 및 $\mathrm{BXv})$ 로, $\mathrm{IS} 1542$ 만 삽입된 군은 *S (Bs 및 BYs)로, IS의 삽입이 없었던 군은 $\mathrm{Bn}$ 으로 구분하였다(Fig. 2).

\section{고 찰}

VRE의 내성형 중 VanA형은 vancomycin (MIC, $\geq 64 \mathrm{mg} /$ $\mathrm{L}$ ) 과 teicoplanin ( $\mathrm{MIC}, \geq 32 \mathrm{mg} / \mathrm{L}$ ) 에 획득성, 유도성 내성을 보이며[19], 많은 연구가 이루어져있다[8]. 이와 같은 glycopeptide에 대한 고도내성은 접합에 의해서 내성수여자에게 전달된다. VanA 표현형의 발현을 위한 유전정보는 Tn1546에 의하여 운반 되며 이러한 전위유전단위(transposons)의 확산이 임상적으로 동 정되는 장구균에서 glycopeptide에 대한 고도내성을 유발하는 것 이 알려져 있다[20]. Tn1546은 $10.4 \mathrm{~kb}$ 크기로 총 9개의 단백을 암호화하며, 4 개의 기능성 그룹으로 나누어진다. 즉, 치환기능의 open reading frames (orf1, orf2), 유전발현을 조절하는 vanR, $\operatorname{vanS}$, 실제 내성 발현을 유발하는 효소인 depsipeptide를 암호화 하는 $\operatorname{van} H, \operatorname{van} A, \operatorname{van} X$, 그리고 내성에 필수적이지는 않으나 펩티도글리칸 합성에 관여하는 $\operatorname{van} Y$ 와 $\operatorname{vanZ}$ 로 나누어진다[8, 21, 22].

VRE의 glycopeptide에 대한 내성 기전은 다음과 같다. Glycopeptide를 protein kinase인 VanS의 막횡단 부위의 외부 고리 에서 감지하고, VanS의 cytoplasmic histidine 잔류물(residue)의 자가인산화 후 phosphoryl group이 반응 조절인자(response regulator)인 VanR의 aspartate 잔류물로 전이된다. 인산화된 VanR 은 $v a n H$ 의 promotor sequence에 부착하여 전사를 일으켜 $\mathrm{VanH}$ 를 생산한다. 이어서 $\mathrm{VanH}$ 의 $\alpha$-ketoreductase가 pyruvate를 환 원하여 D-Lac을 생성한다. VanA는 변형된 특이도를 갖는 D-Ala$\mathrm{D}$-Ala ligase로서 VanH에 의하여 생성된 D-Lac에 D-Ala를 연 결한다. 이후 D-Ala-D-Lac 전구체는 UDP-N-acetyl muramide tripeptide에 결합한다. 그러나, 일반적으로 장구균의 염색체에 존 재하는 D-Ala-D-Ala ligase에 의하여 정상적인 D-Ala-D-Ala 전구체도 생성되는데, 이렇게 생성된 $\mathrm{D}-\mathrm{Ala}-\mathrm{D}-\mathrm{Ala}$ 전구체는 $\mathrm{Zn}^{2+}$-dependent dipeptidase인 $\operatorname{VanX}$ 에 의하여 제거된다. 따라 서 세포벽의 전구체는 대부분 내성형으로 구성된다. 또한 $\operatorname{VanY}$ 는 accessory carboxypeptidase로서 $\operatorname{VanX}$ 에 의하여 제거되지 않고 세포질 내에 존재하는 D-Ala-D-Ala 잔류물이 포함된 pentapeptide를 제거하는 역할을 한다. 마지막으로 $\operatorname{VanZ}$ 는 저농도 teicoplanin 내성에 관여한다고 알려져 있으나 정확한 기능은 아 직 명확히 밝혀져 있지 않다[8].

$\mathrm{VRE}$ 의 유전형과 표현형은 일반적으로 일치한다. 즉, vancomycin과 teicoplanin에 내성을 보이는 $\operatorname{Van} A$ 형의 경우 $\operatorname{van} A$ 유 전자를, vancomycin에는 내성이나 teicoplanin에 감수성인 $\operatorname{VanB}$ 형의 경우 $\operatorname{vanB}$ 유전자를 보유한다. 그러나, 최근 $\operatorname{VanB}$ 표현형
을 보이나 $\operatorname{van} A$ 유전자를 가지는 경우가 일본, 태국 그리고 한국 등에서 보고되고 있다[13-16]. Hachimoto 등[13]은 VanB phenotype-vanA genotype VRE의 발생기전으로 내성 발현 초기 단계를 담당하는 vanS domain의 3점 돌연변이로 설명하고 있다. 즉, $\operatorname{vanA}$ 유전자의 발현 조절을 담당하는 $\operatorname{VanS}$ 는 환경내 vancomycin의 존재유무를 감지하여 책임 조절자인 $\operatorname{VanR}$ 에게 신호 를 전달한다. 이후 VanR이 활성화 되어 $\operatorname{VanHAX}$ 의 합성을 유 발한다[8]. 내성 발현의 초기단계를 담당하는 $\operatorname{vanS}$ 의 3점 돌연 변이는 VanS의 아미노산 치환을 유발하고, 이에 따른 teicoplanin 에 대한 반응의 손실이 teicoplanin에 대한 내성 감소를 유발하는 것으로 설명하고 있다. 이후 중국 및 한국에서 $\operatorname{vanS}$ domain의 3 점 돌연변이에 의한 VanB phenotype-vanA genotype VRE 발생 을 보고한 바 있다[14, 15].

본 연구의 teicoplanin에 대한 MIC 검사에서 모든 균주가 teicoplanin에 감수성 혹은 중간을 보여, 28균주 모두 VanB phenotype-vanA genotype VRE로 확인되었다. VanB phenotype$\operatorname{vanA}$ genotype VRE 28균주에서 vanS domain의 유전자 돌연 변이는 없었으며, 이를 통하여 한국에서 발생하는 VanB phenotype-vanA genotype VRE는 일본 및 중국과는 달리 vanS domain의 유전자 돌연변이가 아닌 다른 기전임을 알 수 있었다. $\operatorname{VanB}$ phenotype-vanA genotype VRE 28균주 중 26균주에서 $\operatorname{van} Y$ 의 유전자 변형을 관찰할 수 있었다. 이중 13 개 균주 $(\mathrm{J} 2, \mathrm{~J} 9, \mathrm{~J} 14$, $\mathrm{J} 15$, J20, J22, J24, J25, J27, J28, J10, J12 및 J16)에서는 IS1216V 가 nt8712, nt8832 및 nt8845 위치에 삽입되면서 nt9355까지 총 523-643 bp의 염기 손실이 발생하여 $\operatorname{van} Y$ 의 부분 결실(220-340 $\mathrm{bp)}$ 이 관찰되었다. 이러한 결과는 기존 한국에서 보고된 $\operatorname{VanB}$ phenotype-vanA genotype VRE 5예[16]와 유사하다. 또한, $\operatorname{van} Y$ 유전자 변형을 관찰할 수 있었던 26균주 중 13 균주(J1, J4, $\mathrm{J} 5, \mathrm{~J} 13, \mathrm{~J} 6, \mathrm{~J} 7, \mathrm{~J} 8, \mathrm{~J} 11, \mathrm{~J} 18, \mathrm{~J} 19, \mathrm{~J} 23$, J21 및 J17)에서는 IS$1216 \mathrm{v}$ 의 삽입에 의한 $\operatorname{van} Y$ 및 $\operatorname{van} Z$ 의 완전 결실을 발견할 수 있었다. 저농도 teicoplanin 내성에 관여하는 것으로 알려져 있는 $\operatorname{vanZ}$ 역시 teicoplanin 내성 발현에 역할을 할 수 있다는 가능성 은 제시되었지만, $\operatorname{van} Z$ 유전자만의 변형이 발생한 균주가 관찰되 지 않아 $\operatorname{vanZ}$ 의 손실이 $\operatorname{VanB}$ phenotype-vanA genotype VRE 를 유발했는지의 여부는 확인할 수 없었다. VanB phenotype$\operatorname{vanA}$ genotype $\mathrm{VRE}$ 2개 균주(J3 및 J26)에서 $\operatorname{vanX}$ 의 마지 막 위치인 nt8624와 인접한 nt8649와 nt8694에서 손실이 확인되 었다. 이러한 손실이 $\operatorname{van} X$ 유전자 발현에 영향을 주어 $\operatorname{VanB}$ 표 현형 발생을 유발한 것으로 추정된다.

본 연구 결과를 통하여 한국의 $\operatorname{VanB}$ phenotype-vanA genotype VRE의 발생기전이 일본 및 중국과는 다르며, IS $1216 \mathrm{~V}$ 의 삽입과정과 동반된 $\operatorname{van} X, \operatorname{van} Y$ 및 $\operatorname{van} Z$ 유전자 손실이 주된 기전임을 확인할 수 있었다. 또한 VanB phenotype-vanA genotype $\mathrm{VRE}$ 에 대한 대처는 아직 그 임상적 의의가 정확히 알려져 있지 않아, $\mathrm{VanA}$ 형 $\mathrm{VRE}$ 에 준한 치료가 필요하고 생각되며, 향 후 teicoplanin 투여가능성 및 생체내 감수성에 대한 연구가 필요 
하다고 사료된다.

\section{요 약}

배경 : 최근 일본, 중국 및 한국에서 teicoplanin에 감수성인 $\operatorname{vanA}$ 유전형 vancomycin 내성 장구균(VRE)이 보고되었다. 그 기전으로 vanS domain의 3점 돌연변이와 부단백인 $\operatorname{VanY}$ 혹은 $\operatorname{VanZ}$ 의 결여로 보고된 바 있다. 본 연구에서는 $\operatorname{Tn} 1546$ 의 분석 을 통하여 한국에서의 VanB phenotype-vanA genotype VRE 의 분자생물학적 기전을 밝히고자 하였다.

방법 : 2001년부터 2004년까지 전국에 산재한 8개 대학병원에서 분리된 VanB phenotype-vanA genotype Enterococcus faecium 28균주를 대상으로 하였다. Tn1546의 구조 분석을 위해 PCR 을 시행하였고, 정제된 $\mathrm{PCR}$ 산물을 이용하여 염기서열분석을 하 였다.

결과 : 총 28균주의 VanB phenotype-vanA genotype VRE 모두에서 $\operatorname{vanS}$ domain의 점 돌연변이가 관찰되지 않았지만 $\operatorname{van} Y$ 유전자의 부분 혹은 완전 결실이 관찰되었다. 이 중 13 균주에서 $\operatorname{van} Z$ 유전자의 결실이 동반되었다. 또한 2균주에서 $\operatorname{van} X$ 의 끝 인접부분의 염기 손실이 확인되었다.

결론 : 한국에서 발생하는 $\mathrm{VanB}$ phenotype-vanA genotype $\mathrm{VRE}$ 의 발생은 $\operatorname{vanS}$ domain의 3점 돌연변이에 의한 것이 아닌 $\operatorname{vanX} \operatorname{van} Y$ 및 $\operatorname{vanZ}$ 의 재배열에 의한 것임을 알 수 있었다.

\section{참고문헌}

1. Leclercq R, Derlot E, Duval J, Courvalin P. Plasmid-mediated resistance to vancomycin \& teicoplanin in Enterococcus faecium. N Engl J Med 1988;319:157-61.

2. Uttley AH, Collins CH, Naidoo J, George RC. Vancomycin-resistant enterococci. Lancet 1988;1:57-8.

3. Centers for Disease Control and Prevention. Nosocomial enterococci resistance to vancomycin-United States, 1989-1993. MMWR Morb Mortal Wkly Rep 1993;42:597-9.

4. National Nosocomial Infections Surveillance System. National Nosocomial Infections Surveillance (NNIS) System Report, data summary from January 1992 through June 2004, issued October 2004. Am J Infect Control 2004;32:470-85.

5. Park JW, Kim YR, Shin WS, Kang MW, Han KJ, Shim SI. Susceptibility tests of vancomycin-resistant enterococci. Korean J Infect Dis 1992;24:133-8. (박지원, 김양리, 신완식, 강문원, 한경자, 심상인. Vancomycin내성 enterococci에 대한 감수성 검사. 감염 1992;24:133-8.)

6. Shin JW, Yong D, Kim MS, Chang KH, Lee K, Kim JM, et al. Sudden increase of vancomycin-resistant enterococcal infections in a Kore- an tertiary care hospital: possible consequences of increased use of oral vancomycin. J Infect Chemother 2003;9:62-7.

7. Cetinkaya Y, Falk P, Mayhall CG. Vancomycin-resistant enterococci. Clin Microbiol Rev 2000;13:686-707.

8. Arthur M and Courvalin P. Genetics and mechanisms of glycopeptide resistance in enterococci. Antimicrob Agents Chemother 1993; 37:1563-71.

9. Leclercq R, Dutka-Malen S, Duval J, Courvalin P. Vancomycin resistance gene vanC is specific to Enterococcus gallinarum. Antimicrob Agents Chemother 1992;36:2005-8.

10. Perichon B, Reynolds P, Courvalin P. VanD-type glycopeptide-resistant Enterococcus faecium BM4339. Antimicrob Agents Chemother 1997;41:2016-8.

11. Fines M, Perichon B, Reynolds P, Sahm DF, Courvalin P. VanE, a new type of acquired glycopeptide resistance in Enterococcus faecalis BM4405. Antimicrob Agents Chemother 1999;43:2161-4.

12. McKessar SJ, Berry AM, Bell JM, Turnidge JD, Paton JC. Genetic characterization of $\operatorname{van} G$, a novel vancomycin resistance locus of Enterococcus faecalis. Antimicrob Agents Chemother 2000;44:3224-8.

13. Hashimoto Y, Tanimoto K, Ozawa Y, Murata T, Ike Y. Amino acid substitutions in the vanS sensor of the vanA-type vancomycin-resistant enterococcus strains result in high-level vancomycin resistance and low-level teicoplanin resistance. FEMS Microbiol Lett 2000;185: 247-54.

14. Lauderdale TL, McDonald LC, Shiau YR, Chen PC, Wang HY, Lai $\mathrm{JF}$ et al. Vancomycin-resistant enterococci from humans and retail chickens in Taiwan with unique VanB phenotype-vanA genotype incongruence. Antimicrob Agents Chemother 2002;46:525-7.

15. Eom JS, Hwang IS, Hwang BY, Lee JG, Lee YJ, Cheong HJ, et al. Emergence of van $A$ genotype vancomycin-resistant enterococci with low or moderate levels of teicoplanin resistance in Korea. J Clin Microbiol 2004;42:1785-6.

16. Lee WG, Huh JY, Cho SR, Lim YA. Reduction in glycopeptide resistance in vancomycin-resistant enterococci as a result of van $A$ cluster rearrangements. Antimicrob Agents Chemother 2004;48:1379-81.

17. Clinical and Laboratory Standards Institute. Methods for dilution antimicrobial susceptibility tests for bacteria that grow aerobically. 7th ed. Approved standard M7-A7. Wayne, Pa: Clinical and Laboratory Standards Institute, 2006.

18. Murray BE, Singh KV, Heath JD, Sharma BR, Weinstock GM. Comparison of genomic DNAs of different enterococcal isolates using restriction endonucleases with infrequent recognition sites. J Clin Microbiol 1990;28:2059-63.

19. Clinical and Laboratory Standards Institute. Performance standards for antimicrobial susceptibility testing. Sixteenth informational supplement, M2-A9 and M7-A7. Wayne, PA: Clinical and Laboratory 
Standards Institute, 2006.

20. Arthur M, Molinas C, Depardieu F, Courvallin P. Characterization of Tn1546, a Tn3-related transposon conferring glycopeptide resistance by synthesis of depsipeptide peptidoglycan precursors in Enterococcus faecium BM4147. J Bacteriol 1993;175:117-27.

21. Arthur M, Molinas C, Courvalin P. Sequence of the van $Y$ gene re- quired for production of a vancomycin-inducible D,D-carboxypeptidase in Enterococcus faecium BM4147. Gene 1992;120:111-4.

22. Arthur M, Molinas C, Courvallin P. The VanS-VanR two-component regulatory system controls synthesis of depsipeptide peptidoglycan precursors in Enterococcus faecium BM4147. J Bacteriol 1992; 174:2582-91. 